\title{
$\begin{array}{r}\text { WAGENINGEN } \\ \text { UNIVERSITY \& RESEARCH } \\ \hline\end{array}$
}

\author{
UAV based soil salinity assessment of cropland \\ Ivushkin, K., Bartholomeus, H., Bregt, A. K., Pulatov, A., Franceschini, M. H. \\ D., Kramer, H., ... Finkers, R.
}

This is a "Post-Print" accepted manuscript, which has been published in "Geoderma"

This version is distributed under a non-commercial no derivatives Creative Commons (c) $(1) \Theta($ (CC-BY-NC-ND) user license, which permits use, distribution, and reproduction in any medium, provided the original work is properly cited and not used for commercial purposes. Further, the restriction applies that if you remix, transform, or build upon the material, you may not distribute the modified material.

Please cite this publication as follows:

Ivushkin, K., Bartholomeus, H., Bregt, A. K., Pulatov, A., Franceschini, M. H. D., Kramer, H., ... Finkers, R. (2018). UAV based soil salinity assessment of cropland. Geoderma. DOI: 10.1016/j.geoderma.2018.09.046

You can download the published version at:

https://doi.org/10.1016/j.geoderma.2018.09.046 


\section{UAV based soil salinity assessment of} cropland

Konstantin Ivushkin ${ }^{1}$, Harm Bartholomeus ${ }^{1}$, Arnold K. Bregt ${ }^{1}$, Alim Pulatov ${ }^{2}$, Marston H.D. Franceschini ${ }^{1}$, Henk Kramer ${ }^{3}$, Eibertus N. van Loo ${ }^{4}$, Viviana Jaramillo Roman ${ }^{4}$, Richard Finkers ${ }^{4}$

${ }^{1}$ Laboratory of Geo-Information Science and Remote Sensing, Wageningen University \& Research, Droevendaalsesteeg 3, 6708 PB Wageningen, the Netherlands

konstantin.ivushkin@wur.nl,harm.bartholomeus@wur.nl, arnold.bregt@wur.nl,marston.franceschini@wur.nl

${ }^{2}$ EcoGIS Center, Tashkent Institute of Irrigation and Agricultural Mechanization Engineers, Qari Niyoziy 39, 100000 Tashkent, Uzbekistan alimpulatov@mail.ru

${ }^{3}$ Wageningen Environmental Research, Wageningen University \& Research, Droevendaalsesteeg 3, 6708 PB Wageningen, the Netherlands henk.kramer@wur.nl

${ }^{4}$ Wageningen Plant Research, Wageningen University \& Research, Droevendaalsesteeg 1, 6708 PB Wageningen, the Netherlands robert.vanloo@wur.nl, viviana.jaramilloroman@wur.nl,richard.finkers@wur.nl

\section{Abstract}

Increased soil salinity is a significant agricultural problem that decreases yields for common agricultural crops. Its dynamics require cost and labour effective measurement techniques and widely acknowledged methods are not present yet. We investigated the potential of Unmanned Aerial Vehicle (UAV) remote sensing to measure salt stress in quinoa plants. Three different UAV sensors were used: a WIRIS thermal camera, a Rikola hyperspectral camera and a Riegl VUX-SYS Light Detection and Ranging (LiDAR) scanner. Several vegetation indices, canopy temperature and LiDAR measured plant height were derived from the remote sensing data and their relation with ground measured parameters like salt treatment, stomatal conductance and actual plant height is analysed. The results show that widely used multispectral vegetation indices are not efficient in discriminating between salt affected and control quinoa plants. The hyperspectral Physiological Reflectance Index (PRI) performed best and showed a clear distinction between salt affected and treated plants. This distinction is also visible for LiDAR 
measured plant height, where salt treated plants were on average 10 centimetres shorter than control plants. Canopy temperature was significantly affected, though detection of this required an additional step in analysis - Normalised difference Vegetation Index (NDVI) clustering. This step assured temperature comparison for equally vegetated pixels. Data combination of all three sensors in a multiple linear regression model increased the prediction power and for the whole dataset $\mathrm{R}^{2}$ reached 0.46 , with some subgroups reaching an $\mathrm{R}^{2}$ of 0.64 . We conclude that UAV borne remote sensing is useful for measuring salt stress in plants and a combination of multiple measurement techniques is advised to increase the accuracy.

Keywords: UAV, remote sensing, soil salinity, quinoa, LiDAR, Hyperspectral, Thermography

\section{Introduction}

Increased soil salinity is a significant agricultural problem that decreases yields for common agricultural crops (Maas and Grattan, 1999). Moreover, soil salinity is a dynamic phenomenon which makes timely soil salinity data essential for agricultural management of affected regions. Remote sensing can provide the necessary spatial and temporal resolution, but widely acknowledged methods and techniques for soil salinity monitoring of cropland using remote sensing are not present yet. Most of them propose to use vegetation indices, Normalised Difference Vegetation Index (NDVI) being the most popular(Rahmati and Hamzehpour, 2017; Zhang et al., 2015). Other plant parameters, like remotely sensed canopy temperature (Ivushkin et al., 2017; Ivushkin et al., 2018), have been applied as a proxy for soil salinity. Bare soil remote sensing was also used, though less often (Bai et al., 2016; Nawar et al., 2014). This can be explained by the fact that upper layer of soil does not reflect actual salinity levels in root zone, which is the most important information for agriculture.

Though the above mentioned studies reported high correlations and accuracies of prediction in some situations, their application on other study areas did not show the same usability and accuracy (Allbed et al., 2014; Douaoui et al., 2006). Moreover, widely available satellite images cannot provide high spatial resolution and temporal flexibility of data acquisition, which are important for agricultural application.

One of the solutions to overcome the issues of scale, resolution and temporal flexibility is the use of Unmanned Aerial Vehicles (UAV) as a sensor platform. UAV-based remote sensing is currently used for a wide range of applications in agriculture and soil science. These applications include but are not limited to: soil erosion monitoring (Oleire-Oltmanns et al., 2012), crop and soil mapping for precision farming (Honkavaara et al., 2013; Sona et al., 2016), quantifying field-based plant-soil feedback (van der Meij et al., 2017) and measuring physiological indicators of crops (Domingues Franceschini et al., 2017; Roosjen 
et al., 2018). There is an increasing amount of operational UAV service providers in agriculture industry and many farmers start to maintain their own fleet. All this makes UAV's widely available remote sensing platforms with vast potential applications, including soil salinity monitoring.

Several studies discuss the potential of UAV-borne remote sensing for soil salinity and water deficit stresses, which often leads to a similar stress response in plants. Romero-Trigueros et al. (2017) investigated Citrus species grown under deficit irrigation with reclaimed water of increased salinity. They found that Red and Near Infrared spectral bands are significantly correlated with the chlorophyll content, stomatal conductance and net photosynthesis and concluded on the feasibility of an UAV-borne imagery to assess physiological and structural properties of Citrus under water and saline stress. Quebrajo et al. (2018) used thermal imagery from a UAV mounted camera to detect water stress in sugar beet plants. They concluded that this a reliable method to monitor the spatio-temporal variations of crop water use in sugar beet fields, but further research is required to propose optimal recommendations for a specific plant species.

These examples show that effects of salt and water stress in plants are definitely detectable by UAV remote sensing systems, but UAV's specific application for salinity stress was investigated only in one of them (Romero-Trigueros et al., 2017) and with the focus on water stress rather than salinity stress. Therefore, considering that available research on the topic is limited, we have formulated two research questions:

1. Do the UAV sensed variables significantly change in salt treated plants on plot scale?

2. Does a combination of the different variables have an added value?

To answer them we have conducted our research using UAV platforms with three significantly different sensors: thermal camera, hyperspectral camera and Light Detection and Ranging sensor (LiDAR). The research was conducted in the frame of a bigger experiment on salt tolerance of quinoa crop which has been set up on the experimental field at Wageningen University \& Research, the Netherlands. 


\section{Methods and materials}

\subsection{Planting experiment set-up}

The experiment was set up on the experimental farm of Wageningen University \& Research located in the central part of the Netherlands. Plants for the experimental trial were sown on March 28, 2017 in a greenhouse, the plants were put outside for cold acclimation on April 21, 2017 and were planted in the

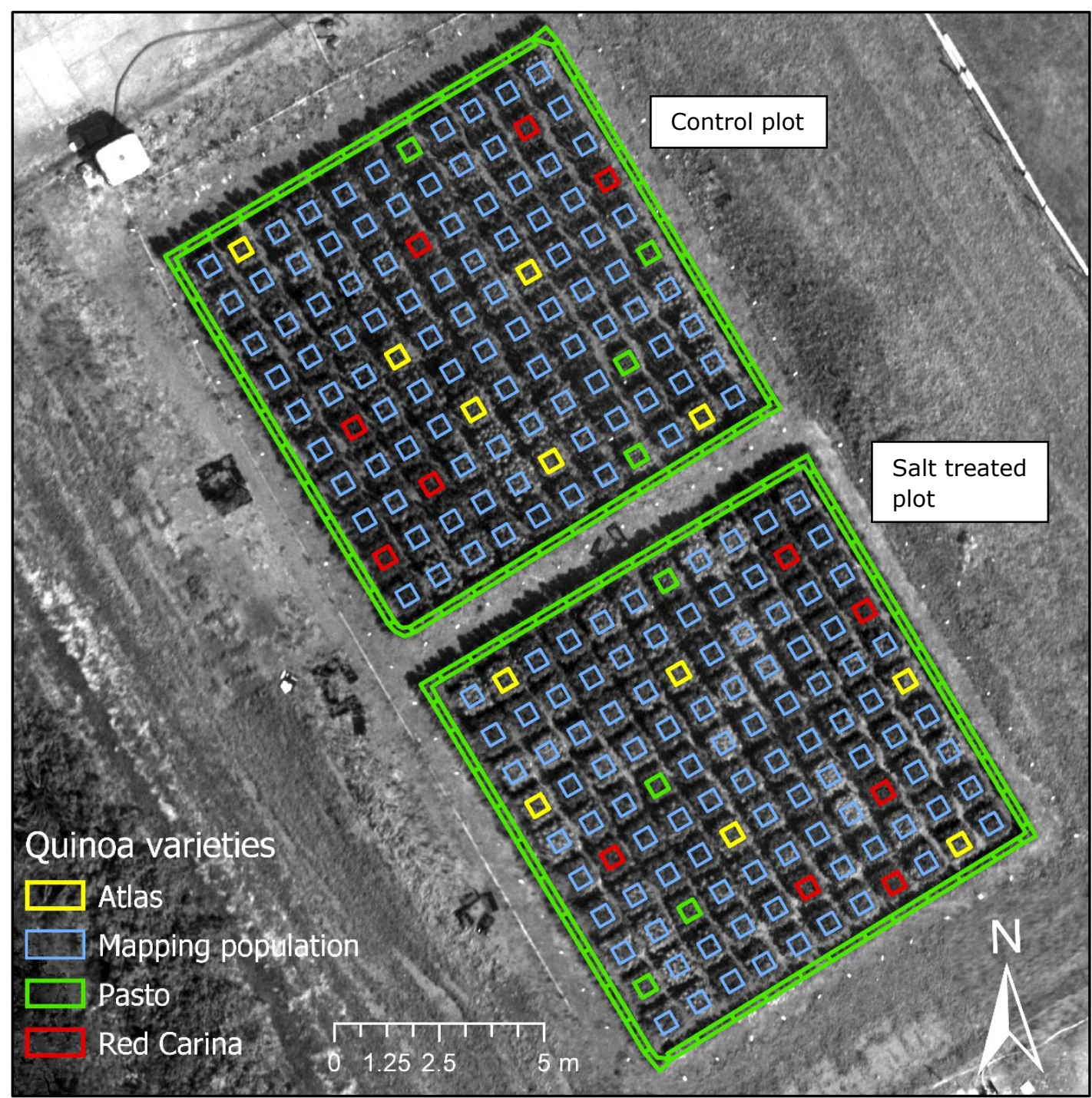

Figure 1. Planting experiment spatial layout. The planting units are marked by the coloured squares on an aerial photo background. Each variety is colour coded.

field on April 24, 2017 (salt trial) and April 25, 2017 (control trial).

The two experimental plots of $13 \times 13$ m were planted with in total 97 different genotypes and varieties of quinoa (Figure 1). The three varieties were Atlas, Red Carina and Pasto. The other 94 genotypes were F3-families of a cross between Atlas and Red Carina. Each plot consists of 110 planting units measuring $60 \times 70 \mathrm{~cm}$ with a gap between the units of $40 \mathrm{~cm}$ (gross unit size $=100 \times 110 \mathrm{~cm}$ ). In the unit, the inner 
$60 \times 70 \mathrm{~cm}$ was planted with 42 plants spaced at $10 \times 10 \mathrm{~cm}$. The southern plot is treated with salt and the northern plot is used as control plot. Around each plot of 110 planting units, an edge row of Pasto plants was planted in order to make sure the light conditions of the experimental edge rows was similar to that further away from the edge.

Salt was applied to the salt treated plot in 14 steps to create a final EC of just above $30 \mathrm{dS} / \mathrm{m}$ (equivalent to $300 \mathrm{mM} \mathrm{NaCl}$ ) by adding irrigation water with $\mathrm{NaCl}$, initially at $200 \mathrm{mM}$ and later at 400 $\mathrm{mM} \mathrm{NaCl}$ (Table 1). In the end natural rainfall occurred so frequently, that prior to a rainfall event an equivalent amount of salt was added equal to the amount applied with each $400 \mathrm{mM} \mathrm{NaCl}$ irrigation application. These solid applications quickly dissolved in the rainwater and infiltrated in less than 24 hours.

Table 1. Salt applications. From $11 / 5$ to 30/6 each application was given in irrigation water as 5 L of solution at the mentioned concentration of $\mathrm{NaCl}$.

\begin{tabular}{|l|l|l|}
\hline Date & $\begin{array}{l}\text { mM, concentration } \\
\text { of NaCl solutions }\end{array}$ & $\begin{array}{l}\text { NaCl/planting } \\
\text { unit }\end{array}$ \\
\hline $11 / 5 / 2017$ & 200 & 58 \\
\hline $15 / 5 / 2017$ & 400 & 117 \\
\hline $17 / 5 / 2017$ & 400 & 117 \\
\hline $24 / 5 / 2017$ & 400 & 117 \\
\hline $2 / 6 / 2017$ & 400 & 117 \\
\hline $9 / 6 / 2017$ & 400 & 117 \\
\hline $16 / 6 / 2017$ & 400 & 117 \\
\hline $30 / 6 / 2017$ & 400 & 117 \\
\hline $11 / 7 / 2017$ & as solid & 120 \\
\hline $14 / 7 / 2017$ & as solid & 240 \\
\hline $17 / 7 / 2017$ & as solid & 240 \\
\hline $21 / 7 / 2017$ & as solid & 240 \\
\hline Total (g per planting unit) & & 1717 \\
\hline Total (g per m2) & & 1561 \\
\hline
\end{tabular}

Electrical conductivity was measured at 0-10, 10-20 and 20-30 cm soil depth regularly. For each planting unit, three locations were sampled. Soil samples were weighed fresh and dried in order to see humidity of the current soil. Following this, electric conductivity meter (ProfiLine Cond 315i, Xylem Analytics, Germany) was used to measure the concentration of salts in saturated soil. Twenty grams of soil and 160 $\mathrm{ml}$ of water $(1: 8)$ were mixed and EC of the solution measured by EC meter. During the salt applications, soil samples were taken three days after the treatments. The EC values increased from about $2 \mathrm{dS} / \mathrm{m}$ 
113 (the same level as in the control plot at the start of the season after fertilisation) to about $40 \mathrm{dS} / \mathrm{m}$ in the

114 layer $0-10 \mathrm{~cm}, 15 \mathrm{dS} / \mathrm{m}$ in the layer $10-20 \mathrm{~cm}$ and $18 \mathrm{dS} / \mathrm{m}$ in the layer $20-30 \mathrm{~cm}$ of soil depth (at

115 flowering, after June 16, 2017). EC-levels were variable as they were higher just after application and

116 lower after rainfall events, but gradually increased as mentioned. The level of $40 \mathrm{dS} / \mathrm{m}$ in the top layer

117 exactly reflects the $\mathrm{NaCl}$ concentration of $400 \mathrm{mM}$ used in the application. The surface soil salinity of 40

$118 \mathrm{dS} / \mathrm{m}$ corresponds to extremely saline conditions ( $>16 \mathrm{dS} / \mathrm{m})$ and $10-20 \mathrm{~cm}$ values of up to 15

119 correspond to highly saline conditions (8-16 dS/m). In general, experimental setup corresponds to

120 highly-extremely saline conditions where only tolerant species can grow.

121 The total irrigation plus rainfall from planting to harvest (on August 7, 2017) was $229 \mathrm{~mm}$. The initial soil

122 moisture content was about $100 \mathrm{~mm}$ (30\% relative water content taken over the first $30 \mathrm{~cm}$ soil). At

123 harvest the relative water content was about $20-25 \%$ (or $60-75 \mathrm{~mm}$ in the first $30 \mathrm{~cm}$ of soil). So on

124 average the total water use (soil evaporation and transpiration) was about 260-270 $\mathrm{mm}$. 


\subsection{Field measurements of plant variables}

\subsubsection{Stomatal conductance measurements}

The stomatal conductance measurements were taken on two consecutive days from two leaves per one plant in each planting unit twice a day, in the morning and the afternoon using a Decagon SC-1 porometer. The morning measurement took place from 10 to 12 o'clock and afternoon from 13 to 15 o'clock. The standard deviation between the units on control plot is $68 \mathrm{mmol} / \mathrm{m}^{2} / \mathrm{s}$ and on salt treated plot $28 \mathrm{mmol} / \mathrm{m}^{2} / \mathrm{s}$. In our analysis we have used the average value of these four measurements as an estimate of the midday values to ensure best comparison with the UAV flight data which were taken at midday. The stomatal conductance map (Figure 2) is based on these ground measurements and is produced for visualisation and spatial analysis.

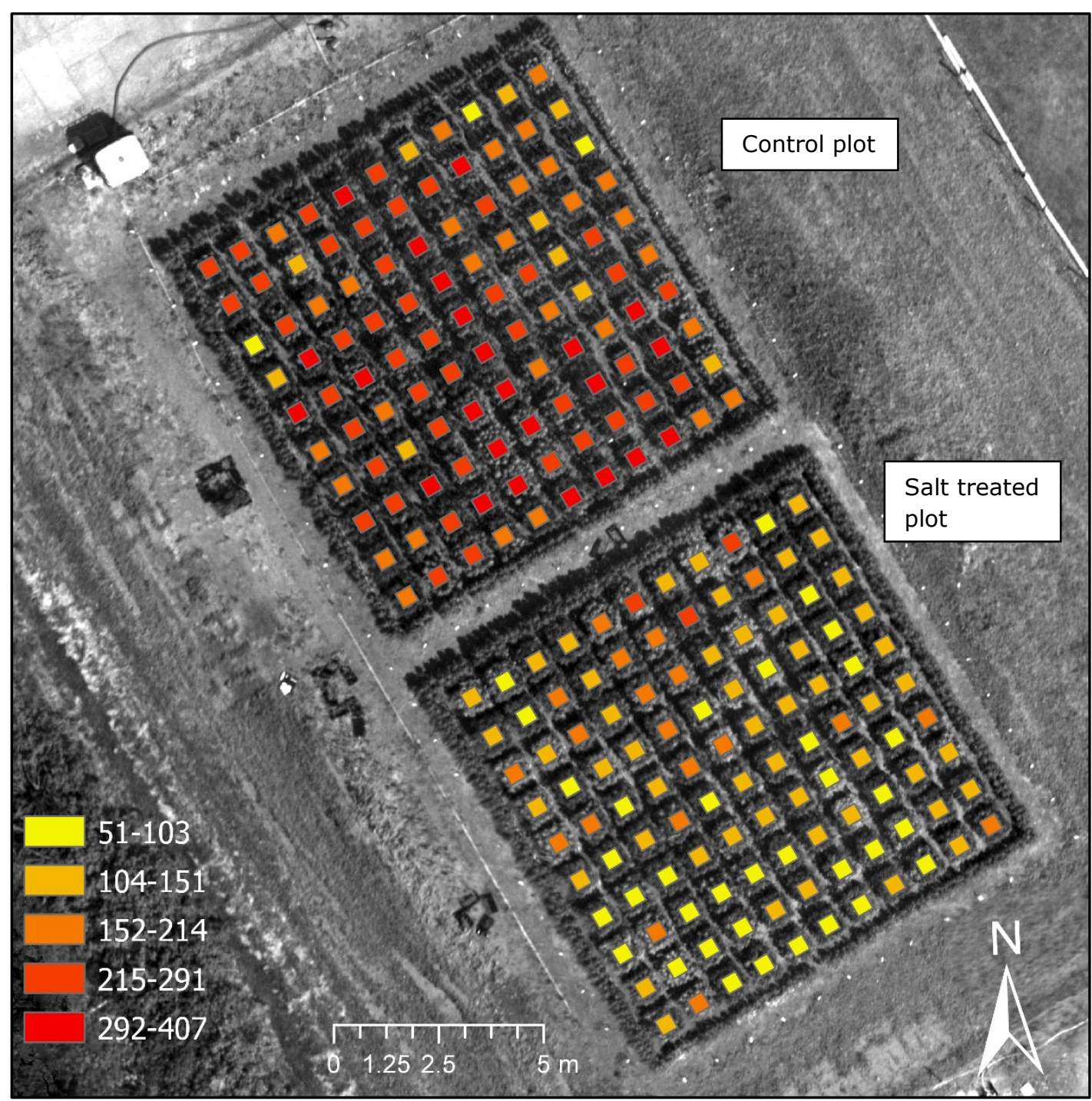

Figure 2. Stomatal conductance map showing the average stomatal conductance per planting unit. Units of stomatal conductance are $\mathrm{mmol} / \mathrm{m}^{2} / \mathrm{s}$ 


\subsubsection{Plant height measurements}

Final plant height was measured after the final harvest (on August 7, 2017) by taking the $90 \%$ quantile of the plant height (so from the 42 plants the longest four plants were excluded, so the length of the $5^{\text {th }}$ longest plant was taken). Plant height was measured from the base of the plant to the top of the head on the main stem using regular ruler.

\subsubsection{Biomass and grain measurements}

After the final harvest, the plants were split into stem (plus some remaining leaves, but most were dead and/or fallen off) and head. The head was dried at $35^{\circ} \mathrm{C}$ until the weight was stable (about 4 days) prior to separating grain and residual head in order to obtain viable seeds for follow-up experiments. The weight of residual head and grain were determined after being dried at $35^{\circ} \mathrm{C}$ and from these dried materials subsamples were taken to determine dry weights after $24 \mathrm{~h}$ drying at $105^{\circ} \mathrm{C}$. Stem weights were also determined after drying at $105^{\circ} \mathrm{C}$. The total biomass (dry weight) is the sum of the dry grain weight, the dry residual head weight and the stem dry weight.

\subsection{UAV data acquisition and processing}

The UAV data used were acquired on $20^{\text {th }}$ of June, 2017. Two flights were made with an Altura AT8, one carrying the hyperspectral camera and the other one with the thermal camera on board. A third flight was conducted with the Riegl Ricopter system, carrying the Riegl VUX-SYS LiDAR system. The systems and data are described in more detail below.

\subsubsection{Hyperspectral data system and processing}

A light weight hyperspectral camera (Rikola Ltd., Oulu, Finland) based on a Fabry-Perot interferometer (FPI) (Honkavaara et al., 2013; Roosjen et al., 2017) has been used. The image produced has a resolution of $1010 \times 1010$ pixels. In total 16 bands were sampled in a range of $515-870 \mathrm{~nm}$ with full width at half maximum (FWHM) varying between 13 and $17 \mathrm{~nm}$, as described in Table 2.

Table 2. Characterization of the spectral bands of the camera.

\begin{tabular}{|l|l|l|l|l|l|l|l|l|l|l|l|l|l|l|l|l|}
\hline $\begin{array}{l}\text { Spectral } \\
\text { bands } \\
\text { centre } \\
(\mathrm{nm})\end{array}$ & 515 & 530 & 550 & 570 & 630 & 670 & 680 & 690 & 700 & 710 & 720 & 740 & 760 & 780 & 800 & 870 \\
\hline $\begin{array}{l}\text { FWHM } \\
(\mathrm{nm})\end{array}$ & 14 & 14 & 13 & 13 & 13 & 13 & 13 & 13 & 13 & 13 & 13 & 13 & 13 & 13 & 13 & 17 \\
\hline
\end{tabular}

The area of the 2 plots was captured in 4 flight lines, parallel to the longest side of the area. The flight height was 20 meters above ground level and the flight speed was 2 meters/second. The overlap 
between flight lines was approximately $80 \%$, within the flight line the overlap between images is approximately $60 \%$. The images were acquired with a ground sampling distance of $0.015 \mathrm{~m}$. The flight lines were constructed with the Unmanned Ground Control Software mission planning software (UGCS, 2017).

Due to intrinsic sensor characteristics, images corresponding to different wavelengths were not registered at the same time, since changes in the wavelengths measured depend on internal adjustment of the sensor system. The mismatch between images corresponding to different wavelengths was solved during photogrammetric processing of the images in Agisoft PhotoScan software (Agisoft LLC, 2017). This procedure depends on implementation of the Structure from Motion (SfM) algorithm, with feature matching, self-calibrating bundle adjustment and image-to-image registration based on overlapping imagery (Harwin et al., 2015). For that, image alignment and dense point cloud derivation were performed using the original resolution of the images (i.e., setting quality to 'high' and 'ultra-high' during these steps in the software processing chain, respectively).

Conversion of digital numbers (registered with 12-bit radiometric resolution) to radiance, in $\mathrm{mW}^{*} \mathrm{sr}^{-1 *} \mathrm{~m}^{-}$ ${ }^{2 *} \mathrm{~nm}^{-1}$, was performed based on dark current measurements, which were taken before the flight, using proprietary software provided with the camera (HyperspectralImager version 2.0). Radiance values were then converted into reflectance factor through the empirical line approach using images, also acquired before the flight, of a Spectralon reference panel with 50\% reflectance (LabSphere Inc., North Sutton, $\mathrm{NH}, \mathrm{USA}$ ), under same general illumination conditions observed during the data acquisition.

\subsubsection{Thermal data processing}

The thermal camera used is a Workswell WIRIS 640 (Workswell s.r.o., Praha, Czech Republic). This thermal camera captures images with $640 \times 512$ pixels resolution, and has a temperature sensitivity of $0.05^{\circ} \mathrm{C}$, with a spectral range of $7.5-13.5 \mu \mathrm{m}$. The default setting for emissivity of 0.95 was used. The thermal camera captures calibrated images which means that the actual temperature is recorded.

The area of the 2 plots was captured in 4 flight lines, parallel to the longest side of the area. The flight height was 20 meters above ground level and the flight speed was 2 meters/second. The overlap between flight lines was approximately $80 \%$, within the flight line the overlap between images is approximately $60 \%$. The images were acquired with a ground sampling distance of $0.025 \mathrm{~m}$. The flight lines were constructed with the Unmanned Ground Control Software mission planning software (UGCS, 2017). 
The calibrated images were processed with Agisoft PhotoScan software (Agisoft LLC, 2017) where a mosaic for the whole trial has been constructed. Unfortunately, the GPS malfunctioned during the acquisition so no GPS coordinates were available for the imagery. Since the images were captured with sufficient overlap (70\%), PhotoScan still can construct a mosaic applying the Structure from Motion (SfM) algorithm, but the result is without geo-reference. The geo-referencing was done manually in ArcMap (ESRI, 2016) by selecting recognizable locations on the thermal mosaic and a georeferenced hyperspectral image of the area.

\subsubsection{Lidar height measurements and data processing}

The RIEGL RiCOPTER with VUX®-1UAV (RIEGL Laser Measurement Systems GmbH, Horn, Austria) integrated UAV and sensor system has been used for LiDAR data acquisition. The RiCOPTER is a batterydriven octocopter with an empty weight (no batteries and equipment) of $9 \mathrm{~kg}$ that can carry a payload of up to $8 \mathrm{~kg}$. Together with the VUX®-1UAV scanner $(3.75 \mathrm{~kg})$, the system controller $(0.9 \mathrm{~kg})$, the IMU $(0.7 \mathrm{~kg})$ and optional cameras the total system weights just under $25 \mathrm{~kg}$. The batteries allow flight times of up to $30 \mathrm{~min}$ at $30 \mathrm{~km} / \mathrm{h}$ maximum cruise speed. This allows flying multiple overlapping flight lines to increase target coverage (Brede et al., 2017).

The VUX®-1UAV is a survey-grade laser scanner that is mounted underneath the RiCOPTER. It uses a rotating mirror with a rotation axis in flight direction to direct the laser pulses and achieve an acrosstrack Field Of View (FOV) of $330^{\circ}$ perpendicular to the flight direction. This means that lateral flight line overlap is only restricted by the maximum operating range of the laser. An Applanix AP20 IMU attached to the VUX®-1UAV and Global Navigation Satellite System (GNSS) antennas on top of the RiCOPTER record flight orientation and GNSS data. The on-board instrument controller manages all sensors' data streams and includes a 220GB SSD storage, which is sufficient for several missions (Brede et al., 2017).

The area of the 2 plots was captured in 6 flight lines, 3 parallel to the longest side of the area, situated to the left, middle and right of the plots and 3 parallel to the shortest side of the area, also situated to the left, middle and right of the plots. This way, the quinoa plants are scanned from all sides. For each flight line a scan line is captured. The flight lines were constructed with the Unmanned Ground Control Software mission planning software (UGCS, 2017).

Pre-processing of the trajectory data (flight orientation and GNSS data) was performed with the POSPac Mobile Mapping Suite (Applanix, 2017) using base station data provided by 06-GPS (06-GPS, 2017). This makes it possible to achieve centimetre accuracy for the geo-location of the laser data. 
Processing of the raw scanning data was done with the RIEGL RiPROCESS software which is the default software tool for processing data from the VUX®-1UAV scanner. With RiPROCESS, the raw data is converted to a geo-referenced point cloud using the pre-processed trajectory data for accurate geopositioning. Internal co-registering of the different scan line data was carried out with the RiPRECISION tool. This tool finds matching control planes between scan lines and performs the co-registration. The resulting LiDAR point cloud data was exported as LAS files for further processing with the LAStools software (rapidlasso $\mathrm{GmbH}, 2017$ ).

Classification of ground points and calculation of the plant height was done with the LAStools software suite. For ground point classification, the lasground_new tool was used with the wilderness option. This enables the detection of smaller features on the ground in high resolution LiDAR. The results were visually evaluated and the pattern of the ground classification was found accurate enough for further processing. Next, the height of all points above the ground was calculated with the lasheight tool. The result is still a point cloud with the $Z$ value of each point is the relative height above the ground. The $Z$ value for ground points is 0 . This point cloud was rasterized into a raster file with the lasgrid tool using the highest option with a step size of $2.5 \mathrm{~cm}$. This means that within a grid cell of 2.5 by 2.5 centimetres the highest $Z$ value of LiDAR points that fall within this grid is assigned as value to the grid cell. The result is a raster file covering the whole plot area with the maximum height of the vegetation per 2.5 by $2.5 \mathrm{~cm}$ 's. This file is used to derive statistical information about the plant height for each planting unit.

\subsection{Vegetation indices calculation}

Three vegetation indices were calculated for the research. The first one is well known and broadly used Normalised Difference Vegetation Index (NDVI):

$$
N D V I=\frac{N I R-R}{N I R+R}
$$

The second one is Optimized Soil Adjusted Vegetation Index (OSAVI) (Rondeaux et al., 1996), calculated as:

$$
O S A V I=\frac{N I R-R}{N I R+R+0.16}
$$

In our calculation NIR is the reflectance at $870 \mathrm{~nm}$ and R is reflectance at $690 \mathrm{~nm}$ spectral band. The third index is PRI (Gamon et al., 1992), calculated as:

$$
P R I=\frac{\mathrm{R} 531-\mathrm{R} 570}{\mathrm{R} 531+\mathrm{R} 570}
$$

where $\mathrm{Rx}$ is the reflectance on the corresponding wavelength in $\mathrm{nm}$. PRI is known to be responsive to salinity stress in plants (Zinnert et al., 2012). 


\subsection{NDVI clustering}

254 To filter out the influence of the total biomass on a UAV measured temperature we applied NDVI 255 clustering. In this way we ensure that we compare the temperatures of the equal amount of a plant material per pixel. The clusters were created by sorting the plant units based on their average NDVI value and assigning them into groups of equal size. A total 5 clusters were established each containing

25824 planting units, which means that 120 planting units were included into regression analysis. NDVI ranges for each class are indicated in Table 3.

\subsection{Further geospatial and statistical analysis}

261

262

Further geospatial analysis was implemented in ArcGIS Pro software package (ESRI, 2017). That analysis consisted of calculating average NDVI, PRI, OSAVI and temperature values for each planting unit using Zonal Statistic as Table tool. Then importing of the table into the readable form for IBM SPSS Statistics software (IBM Corp, 2015) for further statistical analysis and plotting. In SPSS correlation coefficients of Table 4 were calculated and boxplots were created. The Multiple Linear Regression model also has been calculated in SPSS software package. For that, functionality of Linear Regression tool has been applied, where canopy temperature, PRI and LiDAR measured plant height were chosen as independent variables. All statistical analysis has been implemented on a planting unit level, therefore average pixel values per planting units were used for producing boxplot graphs and calculating regression and correlation coefficients. 

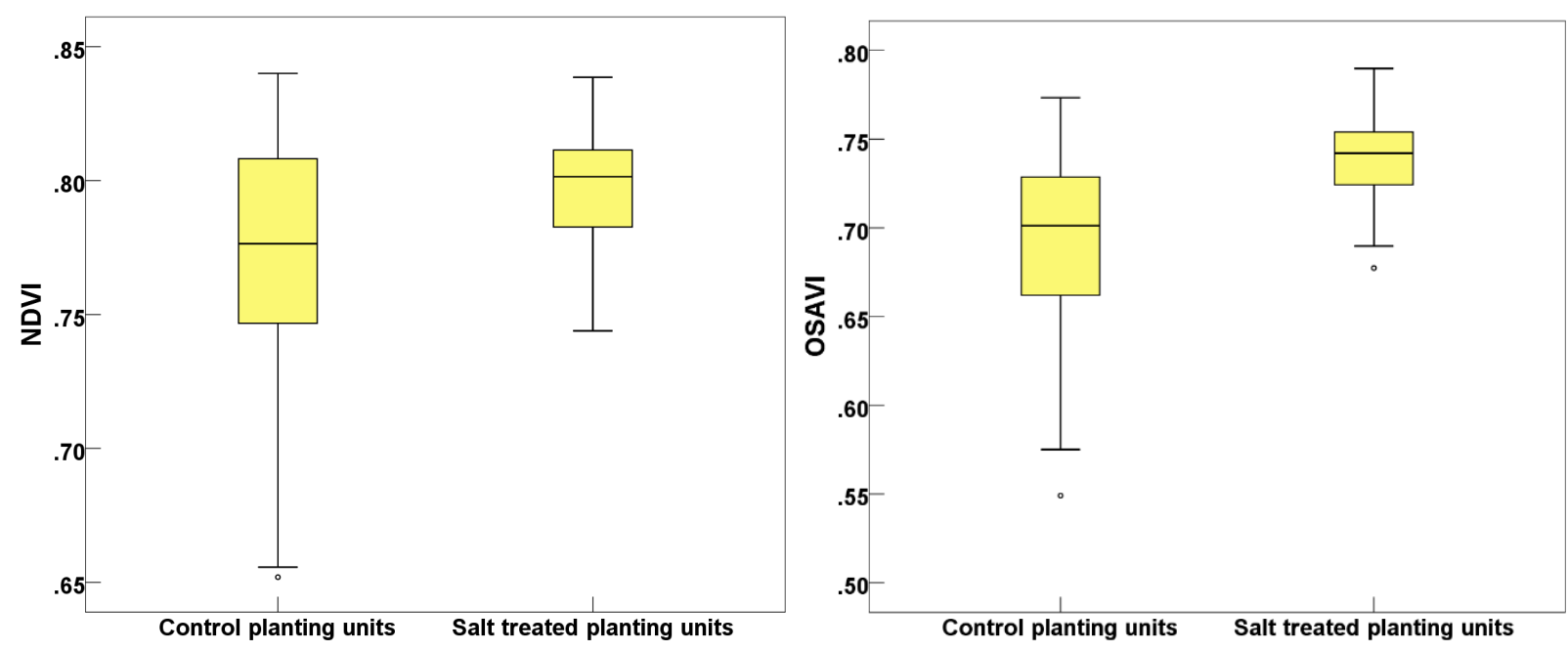

Figure 3. NDVI and OSAVI boxplots of control and salt treated quinoa plots.

274 The multispectral indices did not show

275 significant differences between control

276 and salt treated plots, and to some

277 extent even show an inverted correlation,

278 where both NDVI and OSAVI showed slightly higher values for salt treated planting units (Figure 3 ). We connect this outcome with adaptation mechanisms of quinoa plants. Since quinoa is a wellknown halophyte, it can increase its fresh weight under salinity stress and leaves show the highest increase in weight

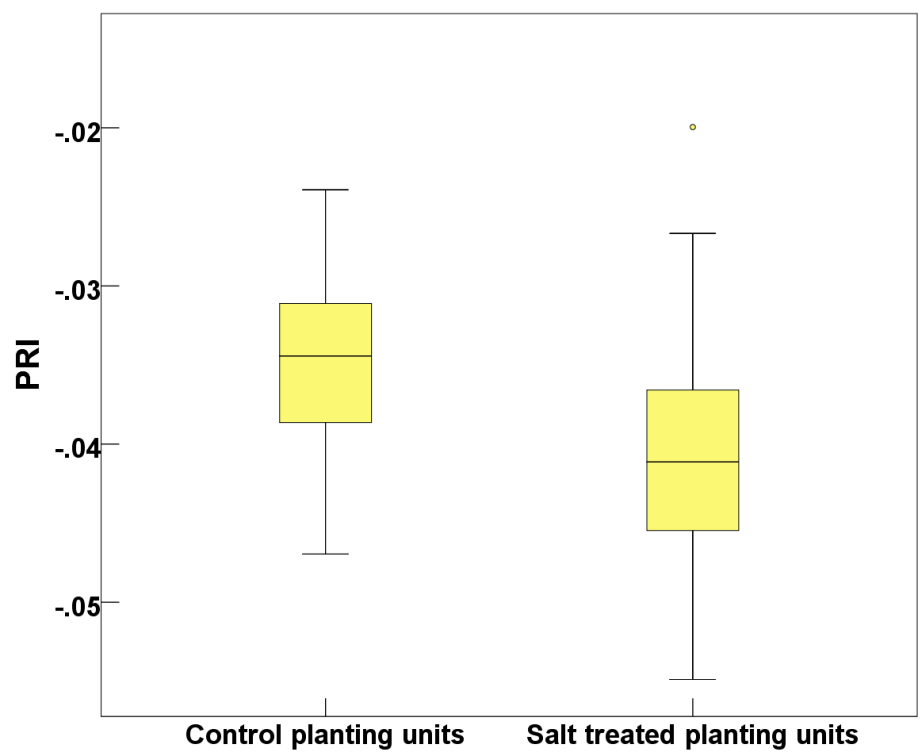

Figure 4. Physiological Reflectance Index (PRI) boxplot (Koyro et al., 2008). This means that multispectral vegetation indices that mainly relate to the greenness and green biomass will not be useful for salt tolerant plants like quinoa, where relationship of salt stress and biomass are not straightforward. 
Even though the total biomass of salt affected plants was slightly higher than for the control, the actual yield was lower (i.e. the harvest index was reduced by the salt treatment), which means that there are certain negative physiological responses even in such salt tolerant plants as quinoa. To detect these responses we have investigated Physiological Reflectance Index (PRI) values, which is known to be influenced by salinity stress (Zinnert et al., 2012). In this case results were more in line with previous studies and showed that PRI values of salt treated plants were lower than for the control (Figure 4). This confirms that actual photosynthetic efficiency has decreased because of the salt stress. Visual assessment of the PRI map in Figure 6 shows these differences, with more reddish colours (higher PRI) on the control plot and more yellow (lower PRI) on salt treated plot. The map also shows that there are quite some inconsistencies and sometimes very low values in control plot and very high in the treated one. Because of this, the differences between two means reached only 0.005 . Suspecting that these

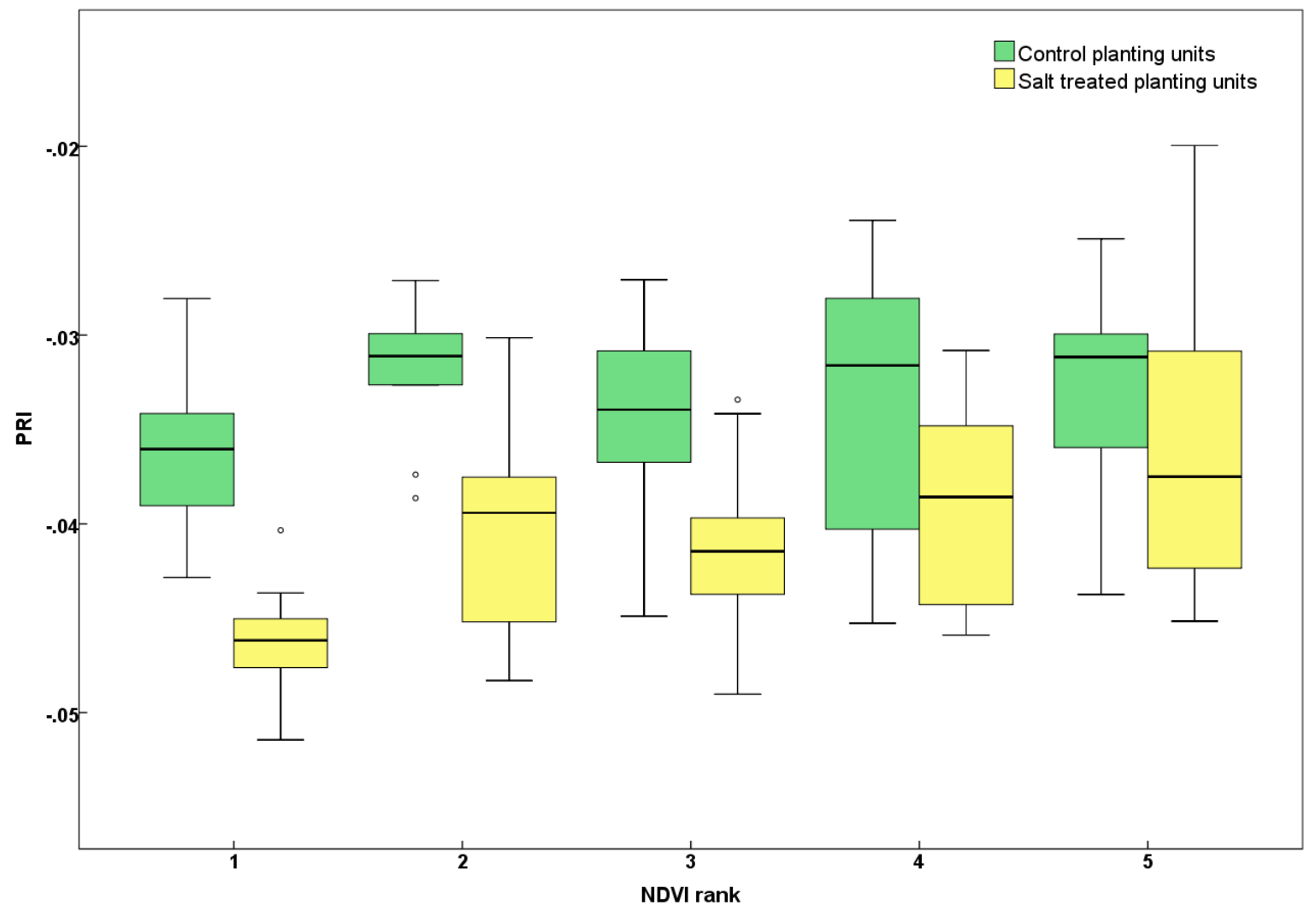

Figure 5. Physiological Reflectance Index (PRI) boxplot for different NDVI clusters inconsistencies appear because of the differences in canopy cover per pixel and not because of actual performance of the plant at the moment of measurement, we applied NDVI clustering (ranges per cluster are in Table 3), as described in the Methods section. This allowed us to compare planting units with comparable canopy cover. In Figure 5 it is visible that application of NDVI clustering increased the differences of means on average twofold, now reaching 0.01 , which leads to a clearer distinction between control and salt treated plants. Therefore NDVI clustering appears to be a useful step in the analysis for plants with non-common salinity stress responses, like quinoa. 


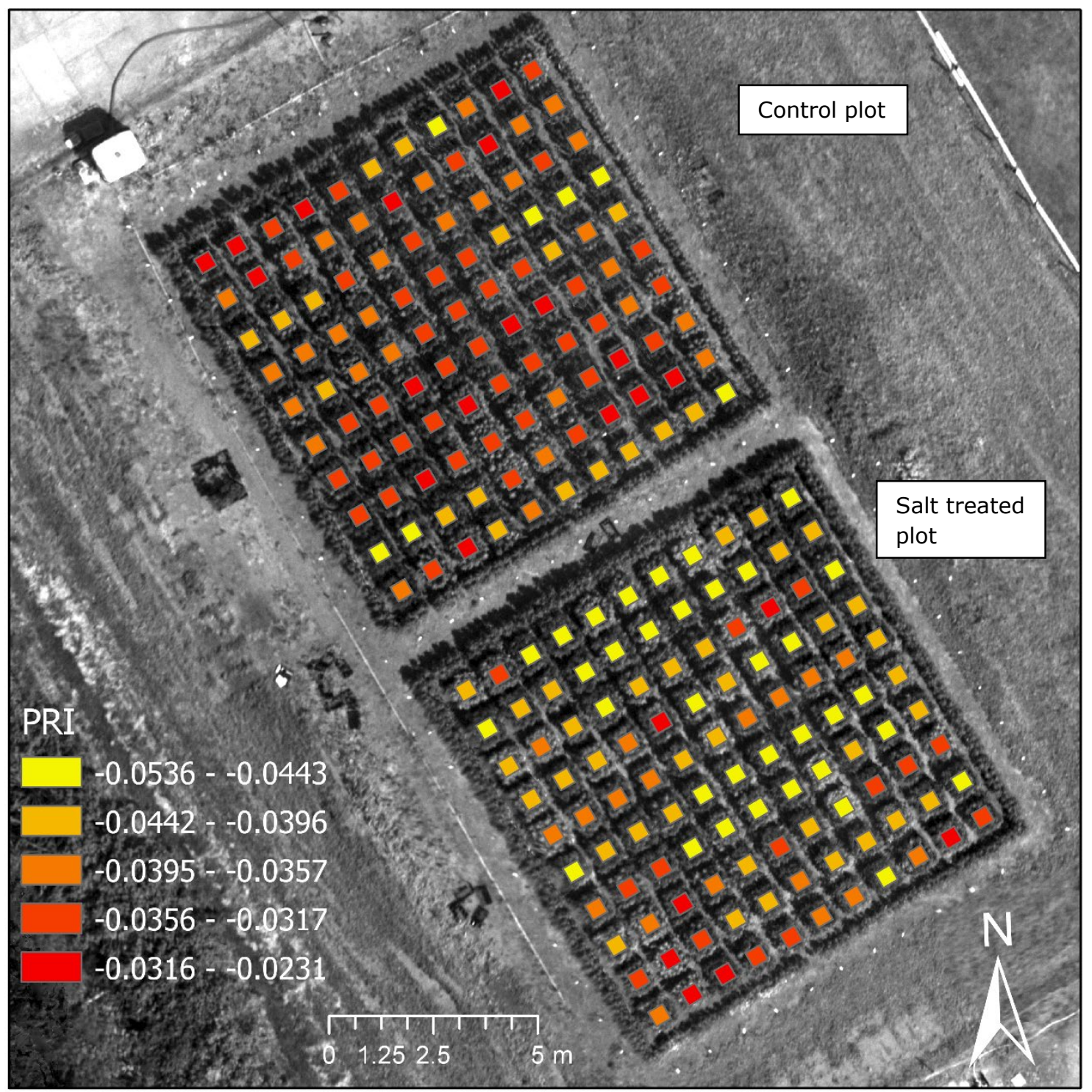

Figure 6. PRI map. The salt treated plot has visibly lower PRI values. 
In addition to differences between control and salt treated plants, PRI was quite variable between different quinoa varieties (Figure 7). Pasto variety showed the most remarkable result because of the inverted relation - salt treated plant showed higher PRI values than control, which suggests that Pasto is the most salt tolerant variety among the three.

These values correspond well with ground measured indicators of plant performance. Red Carina's mean PRI is also slightly higher on salt treated plot,

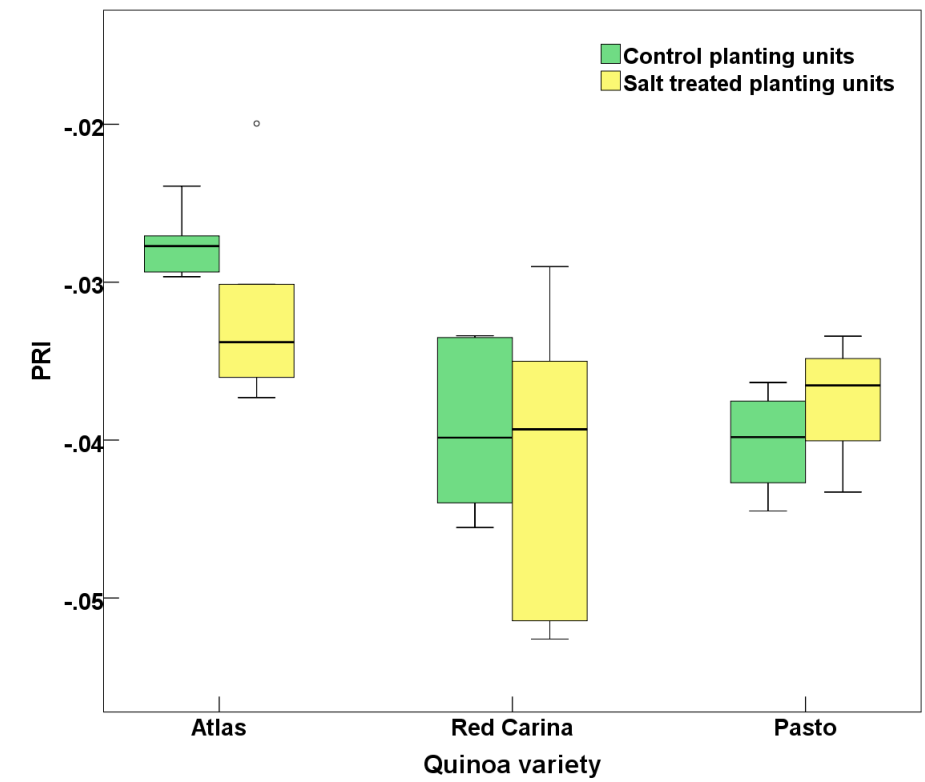

Figure 7. Physiological Reflectance Index (PRI) boxplot clustered by variety but this difference is barely reaching 0.001 and the general boxplot distribution shows that the majority of the values are in the lower range, therefore PRI values in the case of Red Carina are not significantly different between control and salt affected plants. Atlas variety followed a general pattern of reduced PRI on salt treated plants compared to control.

\subsection{Canopy temperature analysis}

Analysis of canopy temperature

differences between saline and non-saline plot are also much clearer when NDVI clustering is applied. Figure 8 shows that when temperature data are stratified only by soil salinity treatment, the temperature measurements are not significantly different. But in case of NDVI clustered analysis, depicted in Figure 9, in 4 out of 5 cases the average temperature of the plant is higher for salt affected plants. This suggests that the general

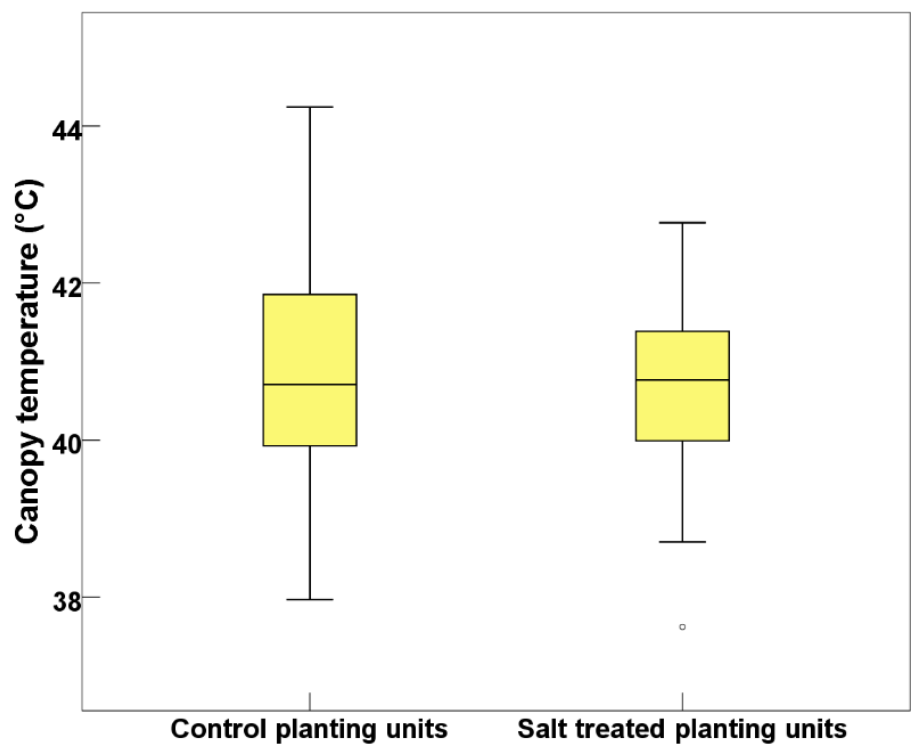

Figure 8. Temperature boxplot for the unclustered dataset. principle of canopy temperature increase in response to salinity, which was previously observed with satellite sensors on landscape scale (Ivushkin et al., 2017; Ivushkin et al., 2018), is also present with aerial data acquired from a UAV on a plot scale. 
The fact that a higher correlation is observed only after NDVI clustering, suggests that even though the canopy temperature is influenced by soil salinity, the amount of vegetation in each pixel is crucial for valid soil salinity assessment.

Moreover, this connection between canopy temperature and soil salinity can be observed in salt tolerant crop, which is a surprising finding, taking into account that salt tolerant and salt sensitive plants have different salt stress adaptation mechanisms (Shabala and Munns, 2012). In this trial this distinguishing was possible by applying additional step in the analysis - NDVI stratification. Therefore, canopy temperature increase in response to salinity stress can be observed in salt tolerant plants, though the effect is less pronounced compared to conventional crops (Ivushkin et al., 2017; Ivushkin et al., 2018).

Canopy temperature generally depends on stomatal conductance. Figure 10 and Table 3 show how they correspond in our case. When the dataset is analysed without any clustering the correlation between stomatal conductance and UAV recorded temperature was -0.188 . This is quite surprising considering that stomatal conductance ground measurements have a clear spatial distribution (Figure 2) which shows significantly lower stomatal conductance on the salt affected plot. The reason for this is the different amount of vegetation signal per pixel and specifics of adaptation mechanism of quinoa, as described before. In this case, though stomatal conductance is decreased with a higher salinity level, the increase in total amount of vegetation per pixel (and, as a result total amount of stomata per pixel) leads to temperature compensation and there is no difference between control and salt affected plot observed in remote sensing data. But when the analysis was done on the NDVI clustered dataset the correlation coefficient reached -0.657 and 3 out of 5 coefficients are significant. However, the two marginal clusters (first and the last) showed low correlation coefficients. This suggests that plants with highest and lowest green biomass of the study area are less suitable for the thermal monitoring of salt induced stress. 
Table 3. Correlation coefficients between stomatal conductance and UAV measured canopy temperature per NDVI cluster (correlation is significant at the $* 0.05$ or $* * 0.01$ level).

\begin{tabular}{|l|c|c|c|c|c|c|}
\hline NDVI rank & 1 & 2 & 3 & 4 & 5 & NDVI unclustered \\
\hline NDVI range & $<0.781$ & $0.781-0.800$ & $0.800-0.809$ & $0.809-0.816$ & $0.816-0.840$ & - \\
\hline Correlation coefficient & -0.285 & $-0.445^{*}$ & $-0.406^{*}$ & $-0.657^{* *}$ & 0.008 & $-0.188^{*}$ \\
\hline
\end{tabular}

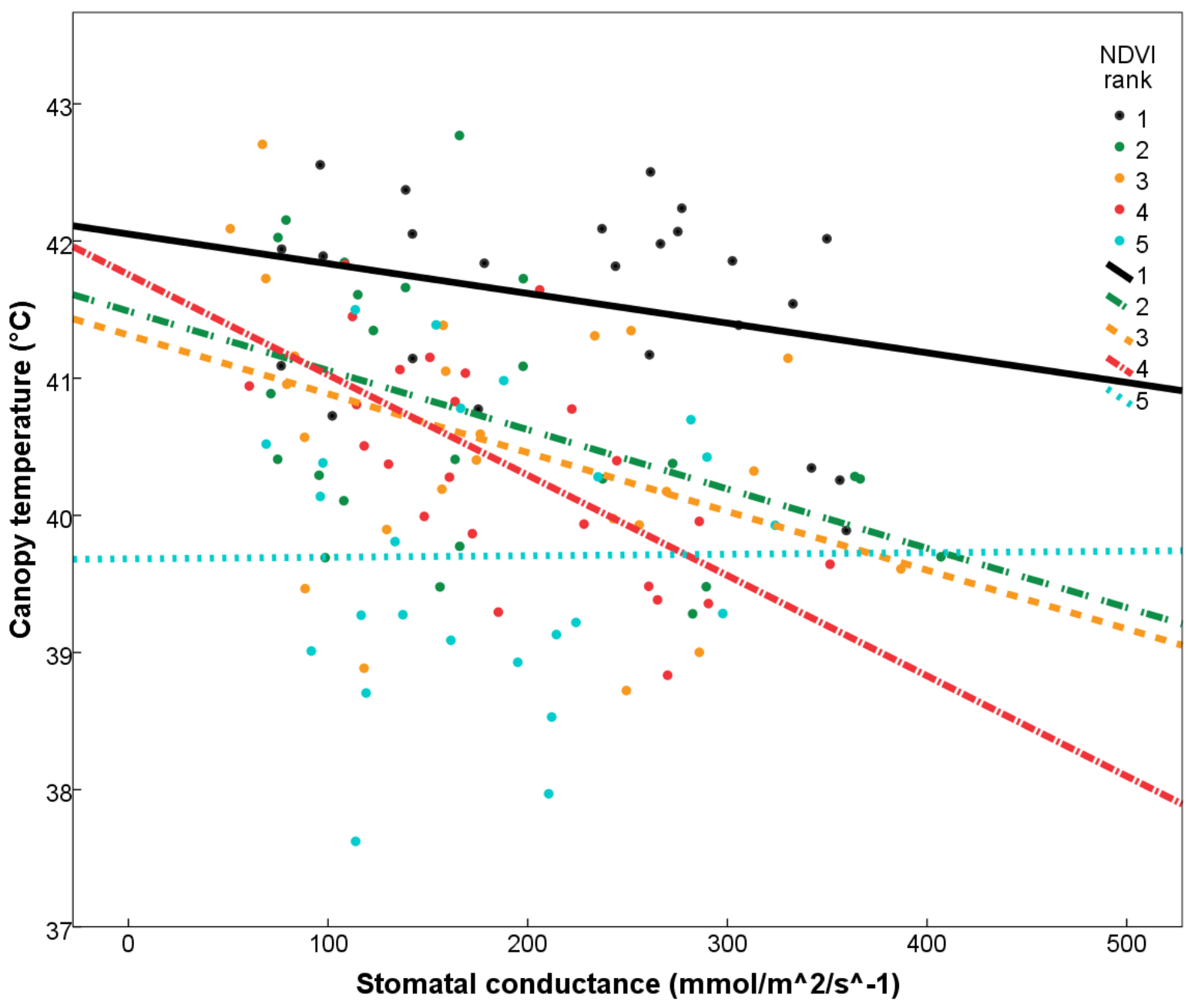

Figure 10. Stomatal conductance vs. canopy temperature scatterplot. Different colours represent different NDVI clusters. Lines are the best fit lines for each cluster. 


\subsection{LiDAR height measurements analysis}

LiDAR measurements of plant height were compared with actual ground measurements. The results show that LiDAR can accurately predict plant height with the $R^{2}$ of 0.78 . This is remarkably good as the height measurements of the LiDAR predict the height of the crop at the harvest 48 days later. That means that LiDAR data has a potential for plant height prediction at the time of harvest, which can further be used for yield prediction.

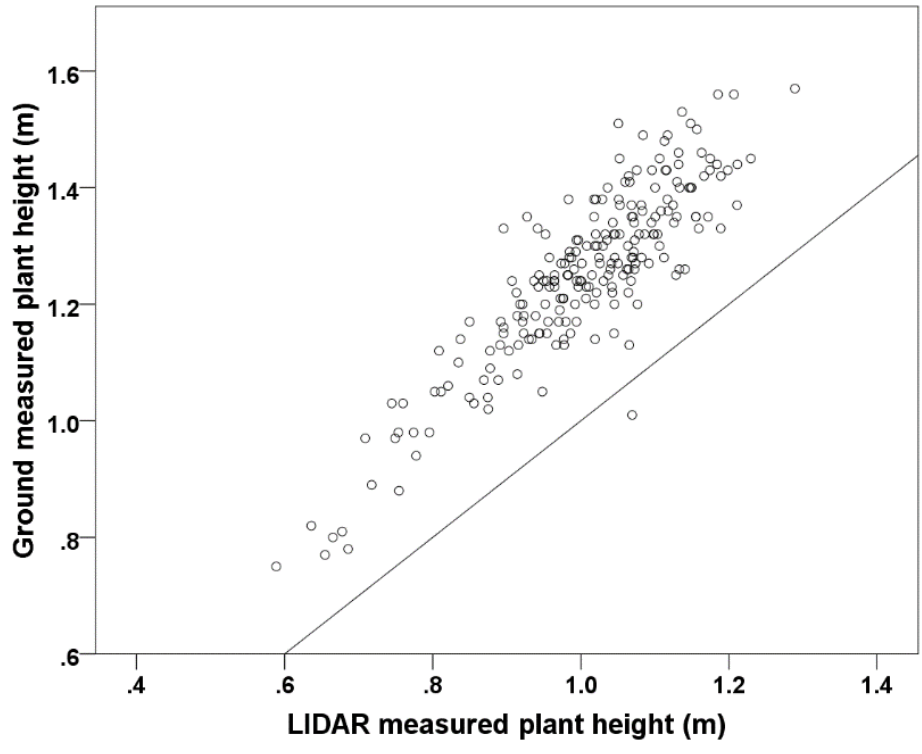

Figure 11. Scatterplot of plant height measured by Lidar and by hand 48 days later. The line is 1:1 line.

Moreover, the $\mathrm{R}^{2}$ most likely has been

decreased by the fact that not every single plant has been measured by ground measurements, but only the $90 \%$ quantile of the plant height of 42 plants was determined, while LiDAR provided an average of every plant's height in each planting unit.

The plant height was significantly affected by salt treatment. The salt treated plants are on average 10 $\mathrm{cm}$ shorter than the control plants (Figure 12). However, this is not true for the Pasto variety, which showed a reversed correlation and salt affected plants are 5-10 cm higher than control. This can clearly be seen on the LiDAR height map, where Pasto can be identified by its difference in height compared to the neighbouring planting units of other varieties (Figure 13).

Considering that plant height is usually affected by salt stress, LiDAR systems have an added value in soil salinity monitoring allowing to obtain plant height measurements over big areas in short period of time. Adding this data into

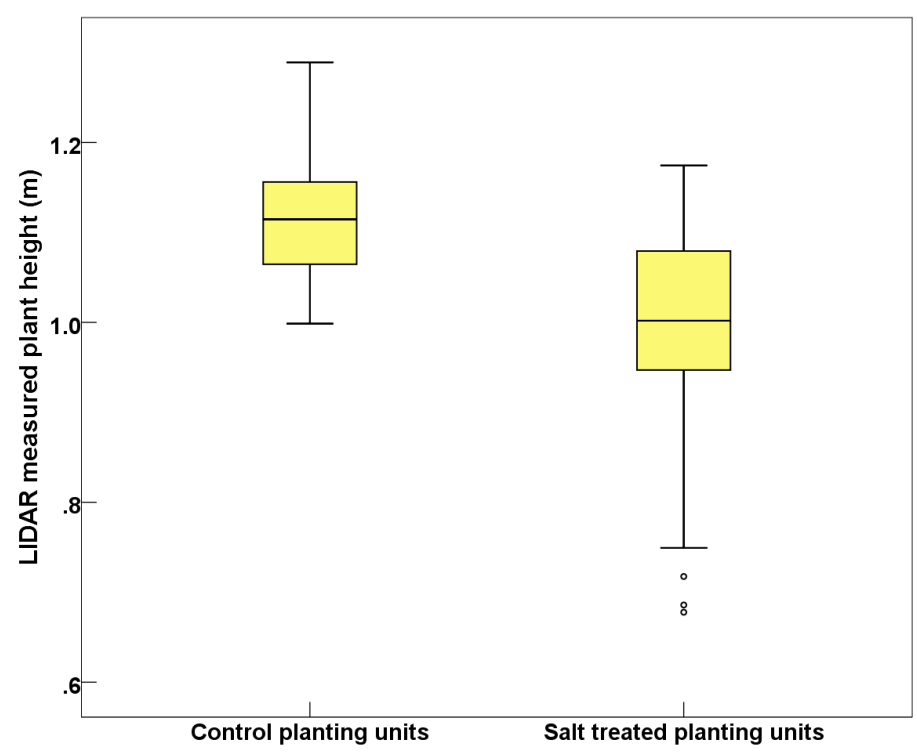

Figure 12. Lidar measured plant height 
multivariable analysis will increase the prediction power and accuracy of the results, which is demonstrated in the next subsection. 


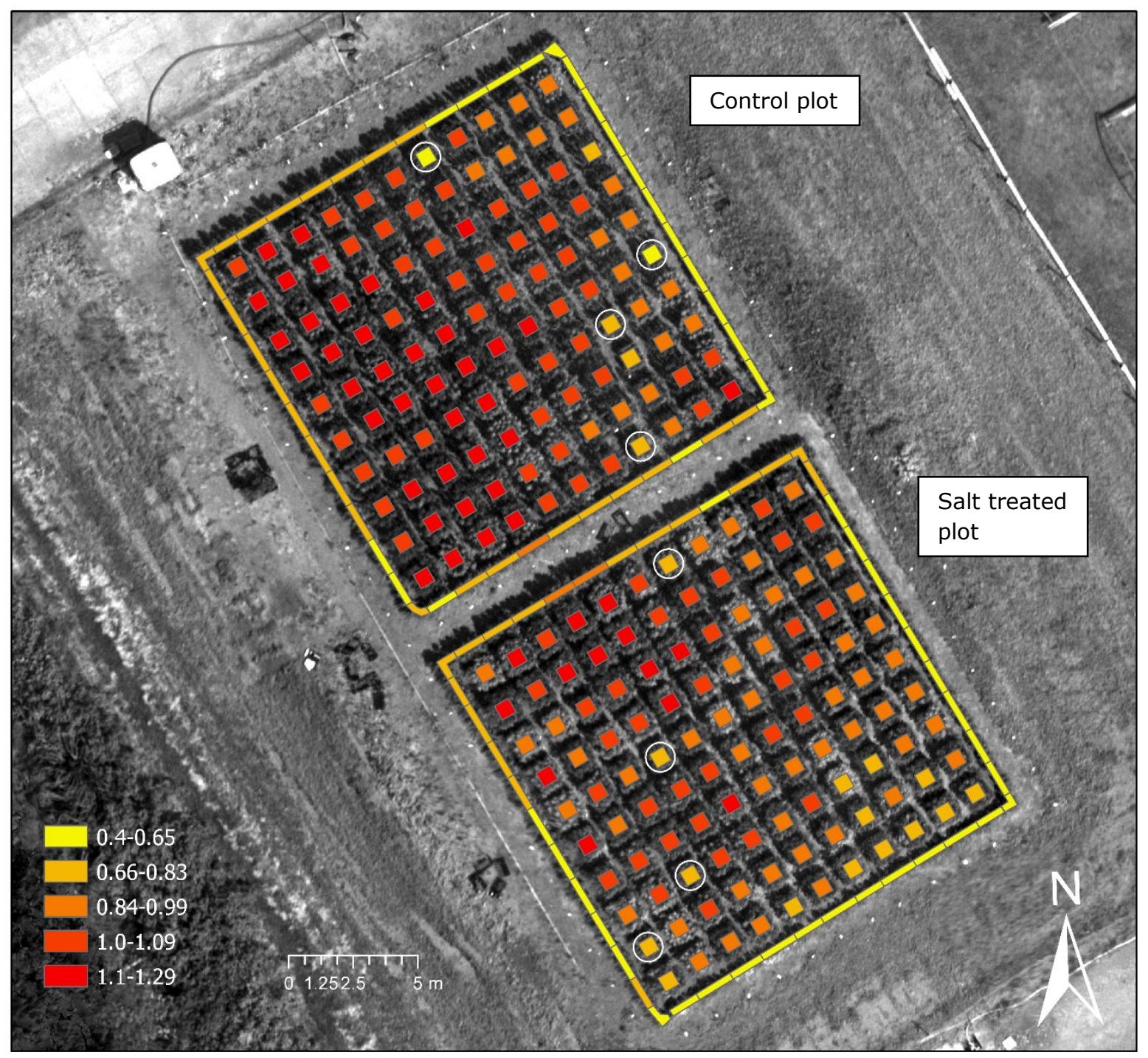

Figure 13. Lidar measured plant height $(m)$ map (Pasto planting units are marked by the circles)

\subsection{Multiple Linear Regression}

Application of Multiple linear regression has showed higher regression coefficient compared to the cases when only a single predictor is used. When data from all three sensors were used (thermal, hyperspectral, LIDAR) the $\mathrm{R}^{2}$ reached $0.64\left(0.58 \mathrm{R}^{2}\right.$

adjusted) for the fourth NDVI class (Table 4) and 0.46 for all classes combined (Figure 14). The predictors in this case were PRI, canopy temperature and LIDAR measured plant height. Though the average regression

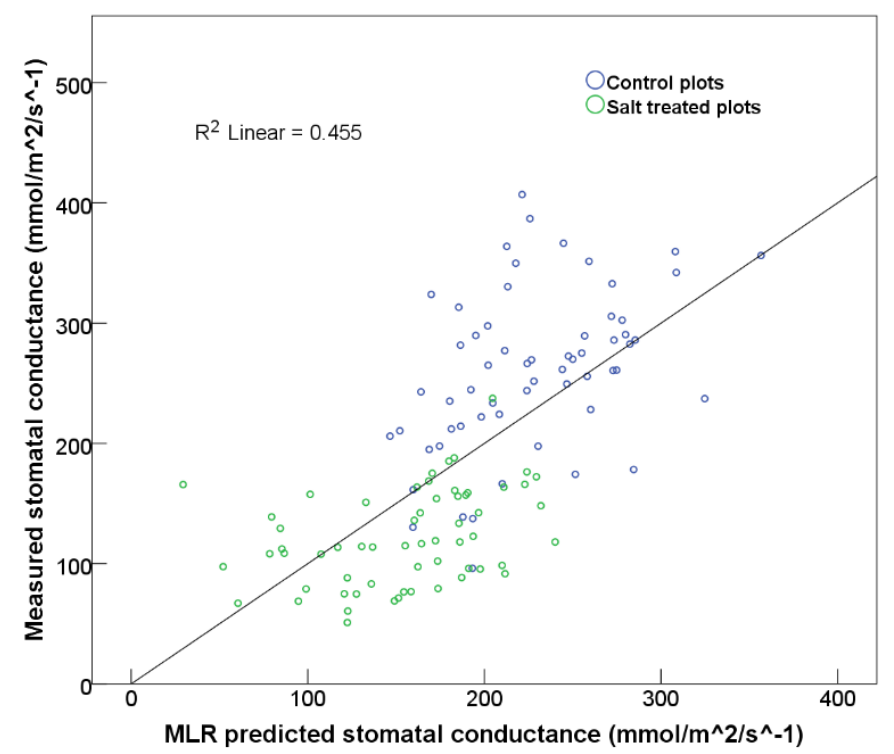

Figure 14. Scatterplot of MLR predicted vs measured stomatal conductance values. The line is 1:1 line. 
coefficient has been increased by application of multiple linear regression, the deviations of the regression coefficients between different NDVI clusters are quite high and $\mathrm{R}^{2}$ varies from 0.1 to 0.64 (Table 4) so there is a room for improvement on the consistency of the results.

Table 4. Determination coefficients $\left(R^{2}\right)$ for different indicators vs. stomatal conductance (MLR combines PRI, canopy temperature and LIDAR measured plant height)

\begin{tabular}{|l|c|c|c|c|c|c|}
\hline NDVI rank & 1 & 2 & 3 & 4 & 5 & NDVI unclustered \\
\hline MLR & .590 & .376 & .410 & .638 & .104 & .241 \\
\hline Canopy temperature & .081 & .198 & .165 & .431 & .000 & .035 \\
\hline PRI & .434 & .184 & .200 & .263 & .043 & .142 \\
\hline LIDAR measured plant height & .487 & .218 & .263 & .417 & .079 & .213 \\
\hline
\end{tabular}

It is fully conceivable that the remote sensing data could be more accurate than the actual stomatal conductance measurements, which were only done using measurements on four leaves and on two different days in a morning and afternoon part. The amount of work does not allow to finish this large number of stomatal conductance measurements on a larger number of leaves within a few hours. This might add bias and residual error in the stomatal conductance measurements. The remote sensing data have been collected in a much shorter period (less bias between different parts of the experiment) and on the whole planting unit instead of only on four leaves per planting unit.

In addition to salt stress, stomatal conductance can be used as an indicator of other stresses, like water stress. Its effective measurements using such cost and labour effective technique as UAV remote sensing can be useful as a component of a precision agriculture systems. In general, remote sensing measurements methods for different plant properties, might be a useful addition for modern agricultural management system, where UAVs are already playing an important role.

Among the directions for a future research we suggest to investigate the application of the method to other crops. It is likely that other crops might have different degree of responses and with more sensitive crops the data analysis might be more efficient by skipping the NDVI stratification step. Though we are sure that the trend will be the same, since general physiological mechanisms are similar in most of the plants. Taking into account that salt treatments in this experiment correspond to highly and extremely affected lands we see an added value in conducting experiment with lesser concentrations, which will correspond to salinity conditions that are more widespread on cultivated lands. 
447 This study investigated plot scale assessment of soil salinity using three different UAV mounted sensors:

448 thermal camera, hyperspectral camera and LiDAR. The results showed that an increase of canopy

449 temperature in response to salt stress is also happening in salt tolerant plants, like quinoa, though this

450 increase is less pronounced. The other variables investigated, namely Physiological Reflectance Index

451 and LiDAR measured plant height, are also affected by soil salinity stress. Physiological Reflectance Index of quinoa plant is significantly decreased because of the increased soil salinity and seems to be a valuable indicator of salt stress, in opposite to multispectral indices like NDVI or OSAVI, which showed insignificant differences between control and salt treated plants, with even reverted correlations. LiDAR measured height of quinoa plant is significantly decreased because of the increased soil salinity. Stratification of an area by NDVI values ensures the equal amount of vegetation per pixel and, therefore, increases the correlation's strength between soil salinity level and remotely sensed physiological variables like PRI and canopy temperature. The combination of multiple remote sensing variables in Multiple Linear Regression model has improved regression coefficient and therefore we conclude that implementation of multiple measurement techniques bears a lot of potential for soil salinity monitoring of cropland by remote sensing. 
06-GPS, 2017. 06-GPS, Sliedrecht, The Netherlands.

Agisoft LLC, 2017. Agisoft PhotoScan Professional 1.3.2, 1.3.2 ed. Agisoft LLC, St. Petersburg, Russia.

Allbed, A., Kumar, L., Aldakheel, Y.Y., 2014. Assessing soil salinity using soil salinity and vegetation indices derived from IKONOS high-spatial resolution imageries: Applications in a date palm dominated region. Geoderma 230-231, 1-8. 10.1016/j.geoderma.2014.03.025

Applanix, 2017. POSPac MMS 7.2. Applanix, Ontario, Canada.

Bai, L., Wang, C., Zang, S., Zhang, Y., Hao, Q., Wu, Y., 2016. Remote Sensing of Soil Alkalinity and Salinity in the Wuyu'er-Shuangyang River Basin, Northeast China. Remote Sensing 8, 163.

Brede, B., Lau, A., Bartholomeus, H.M., Kooistra, L., 2017. Comparing RIEGL RiCOPTER UAV LiDAR Derived Canopy Height and DBH with Terrestrial LiDAR. Sensors (Basel) 17. 10.3390/s17102371

Domingues Franceschini, M.H., Bartholomeus, H., van Apeldoorn, D., Suomalainen, J., Kooistra, L., 2017. Intercomparison of Unmanned Aerial Vehicle and Ground-Based Narrow Band Spectrometers Applied to Crop Trait Monitoring in Organic Potato Production. Sensors (Basel) 17. 10.3390/s17061428

Douaoui, A.E.K., Nicolas, H., Walter, C., 2006. Detecting salinity hazards within a semiarid context by means of combining soil and remote-sensing data. Geoderma 134, 217-230. 10.1016/j.geoderma.2005.10.009

ESRI, 2016. ArcGIS Desktop 10.5, 10.5 ed. Environmental Systems Research Institute, Redlands, CA.

ESRI, 2017. ArcGIS Pro 2.0.1. Environmental Systems Research Institute, Redlands, CA.

Gamon, J.A., Peñuelas, J., Field, C.B., 1992. A narrow-waveband spectral index that tracks diurnal changes in photosynthetic efficiency. Remote Sensing of Environment 41, 35-44. https://doi.org/10.1016/0034$\underline{4257(92) 90059-S}$

Harwin, S., Lucieer, A., Osborn, J., 2015. The Impact of the Calibration Method on the Accuracy of Point Clouds Derived Using Unmanned Aerial Vehicle Multi-View Stereopsis. Remote Sensing 7, 11933.

Honkavaara, E., Saari, H., Kaivosoja, J., Pölönen, I., Hakala, T., Litkey, P., Mäkynen, J., Pesonen, L., 2013. Processing and Assessment of Spectrometric, Stereoscopic Imagery Collected Using a Lightweight UAV Spectral Camera for Precision Agriculture. Remote Sensing 5, 5006.

IBM Corp, 2015. IBM SPSS Statistics 23.0 for Windows, 22.0 ed. IBM Corp., Armonk, NY.

Ivushkin, K., Bartholomeus, H., Bregt, A.K., Pulatov, A., 2017. Satellite Thermography for Soil Salinity Assessment of Cropped Areas in Uzbekistan. Land Degradation \& Development 28, 870-877. 10.1002/ldr.2670

Ivushkin, K., Bartholomeus, H., Bregt, A.K., Pulatov, A., Bui, E.N., Wilford, J., 2018. Soil salinity assessment through satellite thermography for different irrigated and rainfed crops. International Journal of Applied Earth Observation and Geoinformation 68, 230-237. 10.1016/j.jag.2018.02.004

Koyro, H.-W., Lieth, H., Eisa, S.S., 2008. Salt Tolerance of Chenopodium quinoa Willd., Grains of the Andes: Influence of Salinity on Biomass Production, Yield, Composition of Reserves in the Seeds, Water and Solute Relations, in: Lieth, H., Sucre, M.G., Herzog, B. (Eds.), Mangroves and Halophytes: Restoration and Utilisation. Springer Netherlands, Dordrecht, pp. 133-145. 10.1007/978-1-4020-6720-4_13

Maas, E.V., Grattan, S.R., 1999. Crop Yields as Affected by Salinity, in: Skaggs, R.W., van Schilfgaarde, J. (Eds.), Agricultural Drainage. American Society of Agronomy, Crop Science Society of America, Soil Science Society of America, Madison, WI, pp. 55-108. 10.2134/agronmonogr38.c3

Nawar, S., Buddenbaum, H., Hill, J., Kozak, J., 2014. Modeling and Mapping of Soil Salinity with Reflectance Spectroscopy and Landsat Data Using Two Quantitative Methods (PLSR and MARS). Remote Sensing 6, 1081310834. 10.3390/rs61110813

Oleire-Oltmanns, S., Marzolff, I., Peter, K., Ries, J., 2012. Unmanned Aerial Vehicle (UAV) for Monitoring Soil Erosion in Morocco. Remote Sensing 4, 3390. 
Quebrajo, L., Perez-Ruiz, M., Pérez-Urrestarazu, L., Martínez, G., Egea, G., 2018. Linking thermal imaging and soil remote sensing to enhance irrigation management of sugar beet. Biosystems Engineering 165, 77-87. 10.1016/j.biosystemseng.2017.08.013

Rahmati, M., Hamzehpour, N., 2017. Quantitative remote sensing of soil electrical conductivity using ETM+ and ground measured data. International Journal of Remote Sensing 38, 123-140. $10.1080 / 01431161.2016 .1259681$

rapidlasso $\mathrm{GmbH}$, 2017. LAStools 141017, academic. rapidlasso $\mathrm{GmbH}$, Gilching, Germany.

Romero-Trigueros, C., Nortes, P.A., Alarcón, J.J., Hunink, J.E., Parra, M., Contreras, S., Droogers, P., Nicolás, E., 2017. Effects of saline reclaimed waters and deficit irrigation on Citrus physiology assessed by UAV remote sensing. Agricultural Water Management 183, 60-69. 10.1016/j.agwat.2016.09.014

Rondeaux, G., Steven, M., Baret, F., 1996. Optimization of soil-adjusted vegetation indices. Remote Sensing of Environment 55, 95-107. https://doi.org/10.1016/0034-4257(95)00186-7

Roosjen, P., Suomalainen, J., Bartholomeus, H., Kooistra, L., Clevers, J., 2017. Mapping Reflectance Anisotropy of a Potato Canopy Using Aerial Images Acquired with an Unmanned Aerial Vehicle. Remote Sensing 9, 417.

Roosjen, P.P.J., Brede, B., Suomalainen, J.M., Bartholomeus, H.M., Kooistra, L., Clevers, J.G.P.W., 2018. Improved estimation of leaf area index and leaf chlorophyll content of a potato crop using multi-angle spectral data - potential of unmanned aerial vehicle imagery. International Journal of Applied Earth Observation and Geoinformation 66, 14-26. 10.1016/j.jag.2017.10.012

Shabala, S., Munns, R., 2012. Salinity stress: Physiological constraints and adaptive mechanisms, in: Shabala, S. (Ed.), Plant Stress Physiology. CABI Publishing, pp. 59-93.

Sona, G., Passoni, D., Pinto, L., Pagliari, D., Masseroni, D., Ortuani, B., Facchi, A., 2016. Uav Multispectral Survey to Map Soil and Crop for Precision Farming Applications. ISPRS - International Archives of the Photogrammetry, Remote Sensing and Spatial Information Sciences XLI-B1, 1023-1029. 10.5194/isprsarchivesXLI-B1-1023-2016

UGCS, 2017. UgCS 2.10,. UGCS, Riga, Latvia.

van der Meij, B., Kooistra, L., Suomalainen, J., Barel, J.M., De Deyn, G.B., 2017. Remote sensing of plant trait responses to field-based plant-soil feedback using UAV-based optical sensors. Biogeosciences 14, 733-749. $10.5194 / \mathrm{bg}-14-733-2017$

Zhang, T.-T., Qi, J.-G., Gao, Y., Ouyang, Z.-T., Zeng, S.-L., Zhao, B., 2015. Detecting soil salinity with MODIS time series VI data. Ecological Indicators 52, 480-489. 10.1016/j.ecolind.2015.01.004

Zinnert, J.C., Nelson, J.D., Hoffman, A.M., 2012. Effects of salinity on physiological responses and the photochemical reflectance index in two co-occurring coastal shrubs. Plant and Soil 354, 45-55. $10.1007 / \mathrm{s} 11104-011-0955-z$ 